\title{
Synbiotics: Necessity of Today's Meal
}

Narnoliya LK ${ }^{1}$ and Jadaun JS $^{2 *}$

${ }^{1}$ Center of Innovative and Applied Bioprocessing (CIAB), Department of Biotechnology (DBT), Sector-81 (Knowledge City), SAS Nagar, Mohali, Punjab 140306, India

${ }^{2}$ Dyanand Girls Post Graduate College, 13/394, Parwati Bagla Rd, Kanpur, Uttar Pradesh 208001, India

*Corresponding author: Jadaun JS, Dyanand Girls Post Graduate College, 13/394, Parwati Bagla Rd, Kanpur, Uttar Pradesh 208001, India, Tel: +91-512-3202435; Email: jsjdgpg2017@gmail.com

Received date: June 06, 2018; Accepted date: July 04, 2018; Published date: July 11, 2018

Copyright: @ 2018 Narnoliya LK, et al. This is an open-access article distributed under the terms of the Creative Commons Attribution License, which permits unrestricted use, distribution and reproduction in any medium, provided the original author and source are credited.

\begin{abstract}
Synbiotic therapy is a powerful tool of modern medication practices for achieving quick recovery against a vast number of ailments. Synbiotics are the mixed product of prebiotics or dietary fiber and probiotic culture in living form. In clinical trials synbiotics provided superior results over individual treatment of prebiotic and probiotic substances. So these days this is the easiest and cheapest way to modulate the gut microbiome in the favor of good health. Administration of synbiotics is helpful for individuals of all age groups under different kind of disease conditions such as cancer, trauma, allergy, and inflammatory bowl disease and post-surgery infections. Many synbiotic formulations are available in market for public use and research is continue for manufacturing more better of the existing ones for superior activity.
\end{abstract}

Keywords: Disease; Microbiome; Synbiotics; Inflammatory

\section{Introduction}

A typical animal body especially human being, requires a perfect diet for maintaining the homeostasis. By following the dietplan, suitable for a particular age group, we can avoid major menaces caused by the diseases. Most of the sever or sometime lethal diseases are the outcomes of continual imbalance at nutritional level, intake of higher or lower quantity of any element or component in diet can cause flaws in the host body. Due to fast moving and modern life style we are lacking in consumption of good and healthy food, therefore, keeping human health in mind we are compelled to take some supplements in addition to our regular meal. Actually, nutritional status of meal directly or indirectly affect the microbial population of gastrointestinal tract (GIT) up to major extent, because health of host is majorly depend on the ratio of beneficial microbe to harmful one [1].

There are a large number of microbes, approximately ten times higher than the total cells present in human body, were inhabitant on human GIT and mainly these are the members of phyla Bacteroidetes, Firmicutes, and Actinobacteria and collectively these are called as "microbiota" or "microflora" [2,3]. Diversity of microflora of GIT depends on several factors such as intestinal environment, primarily $\mathrm{pH}$, nutritional level of host body, age and health status. Besides these factors abundance of micro flora is also affected by genotypic and environmental factors [4-6]. It is prerequisite, to prevent gut dysbiosis (imbalance of gut microbiota) to reduce the risks of several complications such as gastrointestinal diseases, metabolic disorders, obesity, malnutrition, anemia and food intolerance [7-9]. Colon is the most preferable site for colonization of microbes in GIT tract (from stomach to anus) here more than $70 \%$ of total microbes of body are present [10]. Modulation of gut microbiome could be performed by taking additional supplements and experts suggest administration of prebiotic and probiotics for balancing the micro biota [11]. Probiotics are the living organism either in viable culture or in lyophilized powder form which they positively influence the number of beneficial microbes in gut. Prebiotics were termed for any dietary constituent, which were non digestible carbohydrates; provide growth promoting effect on limited species of gut microbiota [12]. A probiotic may be defined as a pure culture of bacteria, which is one of the member of gut microbiota and its presence should promote the beneficial species and limit the growth of harmful species.

Earlier, probiotic and prebiotic are consumed by the host separately but recent progress in this research area suggest that use of prebiotic and probiotic in combination possess more promising growth promoting effect on gut microbiome, this type of combination therapy termed as synbiotics $[13,14]$.

\section{What are synbiotics?}

A large number of combinations of prebiotic and probiotic can be tried for making the best fusion product having the superior beneficial effects on intestinal environment. Synbiotic therapy fastens the growth rate of useful microbes and simultaneously reduces the abundance of harmful bacteria because prebiotics are the substances which encourage the growth of probiotic microbes as number of probiotic organisms increase density of harmful species goes down. Bacteria of Lactobacillus and Bifid bacterium group are the dominants in gut microbiome and these are able to show some beneficial activities for maintaining the good host physiology [15]. Application of probiotics lead to several advantageous functions such as reduction in frequency of antibiotic associated diarrhea, minimizes the side effects of chemotherapy, lessen the chances of rotavirus infection, modulation of hormonal and immune response, detoxification of compounds, improved lactose intolerance, ant hypertension, production of hypocholesteremic substances, and biotransformation of metabolites [16-20].

Problem associated with probiotics is that their low survival during passages through GIT hence combination with prebiotic could protect them against the enzymatic and chemical reactions of pancreatic juice, bile juice and intestinal fluid. In 1995, Gibson and Roberfroid used the term 'Synbiotic' to describe this combination study of probiotic and 
Page 2 of 5

prebiotic. Here, we reviewed about symbiotic availability in market, their beneficial role against several diseases and its limitations.

\section{Application of synbiotics for human health}

Success of symbiotic formulae depends on the efficiency of both prebiotic and probiotic components used for production of particular synbiotic (Table 1). Till to date, many synbiotic combinations have been prepared and tried in research for promoting the human health but only very few were successful and available in market. In the process of synbiotic products development, Professor Stig Bengmark did a milestone work and in the year 1999 he started a project with his colleagues for the formulation of one of best combination of prebiotic and probiotics [21].

\begin{tabular}{|c|c|c|}
\hline Probiotics & Prebiotics & Synbiotics \\
\hline Lactobacillus genus bacteria & Inulin & Lactobacillus genus bacteria+inulin \\
\hline Lactobacillus and Bifidobacterium genus bacteria & Inulin & Lactobacillus and Bifidobacterium genus bacteria+inulin \\
\hline Lactobacillus and Bifidobacterium genus bacteria & Oligofructose & Lactobacillus and Bifidobacterium genus bacteria+oligofructose \\
\hline Lactobacillus, Bifidobacterium, Enterococcus genus bacteria & FOS & Lactobacillus, Bifidobacterium, Enterococcus genus bacteria+FOS \\
\hline $\begin{array}{l}\text { Lactobacillus, Streptococcus and Bifidobacterium genus } \\
\text { bacteria }\end{array}$ & FOS & Lactobacillus, Streptococcus and Bifidobacterium genus bacteria+FOS \\
\hline $\begin{array}{l}\text { Lactobacillus acidophilus La5, Bifidobacterium lactis Bb-12, } \\
\text { Streptococcus thermophiles and Lactobacillus bulgaricus }\end{array}$ & Oligofructose & $\begin{array}{l}\text { Lactobacillus acidophilus La5, Bifidobacterium lactis Bb-12, Streptococcus } \\
\text { thermophiles and Lactobacillus bulgaricus+Oligofructose }\end{array}$ \\
\hline Bifidobacteria & FOS & Bifidobacteria+FOS \\
\hline Lactobacilli & Lactitol (lactulose) & Lactobacilli+lactitol \\
\hline Bifidobacteria & GOS & Bifidobacteria+GOS \\
\hline Lactobacillus acidophilus P106 & Oat & Lactobacillus acidophilus P106+Oat \\
\hline Lactobacillu ssp & Rice bran derivatives & Rice bran derivatives \\
\hline $\begin{array}{l}\text { Lactobacillus paracaseisp paracasei (FDDVS/Lactobacillus } \\
\text { casei-01 nutrish, Chr. Hansen, Hoersholm, Denmark) }\end{array}$ & FOS & Lactobacillus paracasei sp paracasei+FOS+Soya milk \\
\hline
\end{tabular}

Table 1: Table showing the prebiotic and probiotic component of synbiotic formulations studied under different clinical trial.

For development of this combination they screened more than 500 bacterial cultures, which have better ability to produce antioxidants, anti-inflammatory proteins, especially anti-inflammatory cytokines and more precious quality is to enhance the anti-inflammatory properties of other bacteria. They tested their ability under the simulated conditions of gastric juice i.e., at low $\mathrm{pH} 2.5$ for two hour and also after exposure to $20 \%$ bile for onehour period. After screening test of bacterial strains, they finalized seven bacteria for further study as probiotics and these bacteria were Pediococcus pentosaceus, Leuconostoc mesenteroides, Lactobacillus paracasei F19, Lactobacillus paracasei, Lactobacillus paracasei, Lactobacillus plantarum F5 and Lactobacillus plantarum F26. These bacteria have remarkable characteristics for its application as synbiotics such as they can utilize inuline or amylopectin as solely carbon source, $\beta$-galactosidase producing, antigram positive microbial substances, antimicrobial activity against oral pathogen Candida and gastric pathogen Helicobacter pylori and also reduce symptoms of lactose intolerance.

Further, among these seven, total four strains were finalized for production of synbiotic and development of Synbiotic 2000 which was the concluding point of this study. It is a mixture of four bacteria of Lactobacillus group (Pediacoccus pentosaceus, Leuconostoc mesenteroides, L. paracasei subsp. paracasei and L. plantarum) along with its prebiotic component which contains four fermentable fibers such as $2.5 \mathrm{~g}$ of each beta-glucan, inulin, pectin, and resistant starch (Medipharm AB, Kagerod, Sweden and Des Moines, IA). Recently,
Synbiotic 15, a variant of Synbiotic 2000, is also launched and it contains three bacterial strains ( $L$. Plantarum, L. Paracasei and Pediococcus) instead of four bacterial strains as in Synbiotic 2000.

Synbiotic 2000 and its variant are proved very usefulfor those who suffer with obesity and chronic diseases. Another example of commercial synbiotic is SB3-Synbiotic marketed by an USA company PuoriApS. This is constituted by using strains of Bifidobacterium BB-12 and Lactobacillus fermentum PCC along with vitamin C for boosting of immune system. Protexin company also released a series of synbiotics for example Lepicol (psyllium husk, inulin and 5 strains of live bacteria), Bio-KultInfantis (7 strains of probiotics, high in omega-3 and vitamin D3, FOS and gum acacia as prebiotic), multi-strain BioKult (14 strains of probiotics, soya and traces of milk), Bio-Kult ProCyan (cranberry extract, probiotics and vitamin A) and BioKultCandéa (seven strains of probiotics, garlic and grape fruit seed extract). More details of these products were obtained from a web server.

In the synthesis of a novel synbiotic, rice bran derivatives like RiSolubles, RiceMucil, and Cea100 are used as prebiotic with Lactobacilli species as probiotic [22]. Formulation of 'Synbiotic Yoghurt' has been achieved by combining the Lactobacillus acidophilus P106 with oats and testing of this product on mice revealed that it as a safe and beneficial product [14]. Synbiotic fortified soya milk showed more useful effect on gut microbiome and for production of this product, prebiotic FOS/inulin and probiotic Lactobacillus paracasei $\mathrm{sp}$ 
Page 3 of 5

paracasei (FDDVS/Lactobacillus casei-01 nutrish, Chr. Hansen, Hoersholm, Denmark) were inoculated in soya-milk.

\section{Mechanism of action of synbiotics}

Two components of synbiotic are genuinely differ in their mode of action but their site of action is closely related, probiotic are functional in small and large intestine, although effect of prebiotics is observed mainly in large intestine, so synbiotics spread their effects synergistically [23]. Probiotics has the ability to alter the intestinal milieu by modifying the epithelial and mucosal barrier function through mucosal immunity. These also showed impact on cells of immunomodulation such as dendritic cells, monocytes, macrophages, B-cell, T -cell, epithelial cell [24,25]. Probiotic bacteria resist the growth of other pathogens by producing antimicrobial substances, which lower the luminal $\mathrm{pH}$, preventing the translocation and adherence of bacteria and these antimicrobial substances are termed as bacteriocins. Several bacteriocines were produced by Lactobacillus sp., which restrict the growth of other gram positive bacteria and some gram negative bacteria [26,27]. Synergistic effect of probiotic and prebiotic is confirmed by Nemcova et al. [28] and host microbes presented an enhancement in number of Lactobacilli and Bifidobacterium counts and decrement in counts of Escherichia coli, Clostridia, Enterobacteriaceae bacteria etc. Prebiotics functions as selective growth promoting factor for a dedicated group of probiotic strains. Prebiotics support the growth of probiotics by providing adaptability against luminal environmental variations, whether it may by $\mathrm{pH}$, temperature and oxygenations [29]. Another profit of synbiotic applications is that it reduces the level of toxic metabolites, leading to alleviation of nitrosamines and carcinogenic materials and increases the concentration of short chain fatty acids, ketones, carbon disulfide, and methyl acetates, propionate and butyrate [30,31]. However, mechanism of action of prebiotic on balancing of gut microbe is still not fully understood, although, consequently we can state that synbiotics lead to development of a favorable environment for the growth of selected microbe in intestinal lumen, which resulted in good health of host organism.

\section{Beneficial effects of synbiotics}

A number of clinical trials have been performed for the testing the efficacy of symbiotic treatment under variable level of chronic infections and other diseases. We summarized the achievement of synbiotic approach in medicinal research as follows-

- In control of acute pancreatitis [32,33],

- In reduction of inflammatory bowel disease (IBD) [34,35],

- In curing of trauma [36,37],

- In cancer prevention [38-41],

- In reduction of allergic symptoms $[42,43]$,

- In reduction of incidence of ventilator-associated pneumonia [44],

- Influence on mineral absorption, bone mineral content [45],

- Prevent oral candidiasis [32],

- Reduction of incidence of septic morbidity and postsurgery infections [46,47],

- Improvement in inflammatory diseases [48].

\section{Safety issue of synbiotics}

The well-documented and studied synbiotic is synbiotic 2000. Till date, almost after 10 years of research on the synbiotic, it is highlighted that it comes under safe category and its consumption upto 3 month displayed no side effects. Even there is no side effect reported when its administration was done in critically ill patient, such as HIV infected, liver transplanted, post-surgery and patient with ulcerative colitis $[49,50]$. Actually, both counterpart of synbiotic either Lactobcillus sp. or FOS are approved by FDA under GRAS (generally recognized as safe) category, so automatically the side effects of synbiotic became low. Although, a regularized research is required to observe each and every aspect related to the safety issue because probiotic are microbes and there are more chances of mutations so it is necessary to track their probiotic efficiency in each round of formulations.

\section{Conclusions and Future Prospects}

For living a healthy life, use of synbiotics became popular and need of daily life routine. If we want to maintain balance in microbial population of intestinal lumen, we have to supplement our food with additional probiotics and dietary fibers/prebiotics. It provides immunity against a wide range of infections and allergies. Simultaneously, it is very cheap and it is a natural way to enrich the most diverse and functional part of digestive tract like gut by beneficial microbiota. Any foodstuff, which we consider as prebiotic and each strain of probiotic bacteria have very unique mechanism of action in GIT to provide beneficial symptoms to host health. There is long time of research which is fully dedicated on this aspect but still we are on the periphery of the scientific investigations which is needed for its full understanding of interactions between prebiotic and probiotic to improve the host health. Although, a limited number of synbiotic formulations are available in market as product and also in reach of public domain and a large number of products are in trail but still meaningful research efforts are required to improve the efficacy of the synbiotic formulations.

\section{References}

1. O'Hara AM, Shanahan F (2006) The gut flora as a forgotten organ. EMBO Reports 7: 688-693.

2. Ley RE, Peterson DA, Gordon JI (2006) Ecological and evolutionary forces shaping microbial diversity in the human intestine. Cell 124: 837-848.

3. Kunz C, Kuntz S, Rudloff S (2009) Intestinal flora. Adv Exp Med Biol 639: 67-79.

4. Roberfroid M, Gibson GR, Hoyles L, McCartney AL, Rastall R, et al. (2010) Prebiotic effects: metabolic and health benefits. Br J Nutr 104: S1S63.

5. Kovacs A, Ben-Jacob N, Tayem H, Halperin E, Iraqi FA, et al. (2011) Genotype is a stronger determinant than sex of the mouse gut microbiota. Microb Ecol 61: 423-428.

6. Bolnick DI, Snowberg LK, Hirsch PE, Lauber CL, Org E, et al. (2014) Individual diet has sex-dependent effects on vertebrate gut microbiota. Nat Commun 5: 1-13.

7. Turnbaugh PJ, Ley RE, Mahowald MA, Magrini V, Mardis ER, et al. (2006) An obesity-associated gut microbiome with increased capacity for energy harvest. Nature 444: 1027-1031.

8. Li M, Wang B, Zhang M, Rantalainen M, Wang S, et al. (2008) Symbiotic gut microbes modulate human metabolic phenotypes. Proc Natl Acad Sci USA 105: 2117-2122.

9. Wang J, Tang H, Zhang C, Zhao Y, Derrien M, et al. (2015) Modulation of gut microbiota during probiotic-mediated attenuation of metabolic syndrome in high fat diet-fed mice. ISME J 9: 1-5.

10. Nava GM, Friedrichsen HJ, Stappenbeck TS (2011) Spatial organization of intestinal microbiota in the mouse ascending colon. ISME J 5: 627-638. 
Page 4 of 5

11. Canani RB, Cirillo P, Terrin G, Cesarano L, Spagnuolo MI, et al. (2007) Probiotics for treatment of acute diarrhoea in children: randomized clinical trial of five different preparations. BMJ 335: 340.

12. Singh SP, Jadaun JS, Narnoliya LK, Pandey A (2017) Prebiotic Oligosaccharides: Special Focus on Fructooligosaccharides, Its Biosynthesis and Bioactivity. Appl Biochem Biotechnol 183: 613-635.

13. De Vrese M, Schrezenmeir J (2008) Probiotics, prebiotics, and synbiotics. Food Biotechnology, Springer Berlin Heidelberg pp: 1-66.

14. Mahrous H, El-Kholy WM, Elsanhoty RM (2014) Production of new synbiotic yoghurt with local probiotic isolate and oat and study its effect on mice. Adv Dairy Res 2: 1-7.

15. Gibson GR, Probert HM, Van Loo J, Rastall RA, Roberfroid MB (2004) Dietary modulation of the human colonic microbiota: updating the concept of prebiotics. Nutr Res Rev 17: 259-275.

16. Gibson GR, Roberfroid MB (1995) Dietary modulation of the human colonic microbiota: introducing the concept of prebiotics. J Nutr 125: 1401-1412.

17. Young RJ, Whitney DB, Hanner TL, Antonson DL, Lupo JV, et al. (1998) Prevention of antibiotic-associated diarrhea utilizing Lactobacillus GG. Gastroenterology 114: A435.

18. Saarela M, Mogensen G, Fonden R, Mättö J, Mattila-Sandholm T (2000) Probiotic bacteria: safety, functional and technological properties. J Biotechnol 84: 197-215.

19. Fioramonti J, Theodorou V, Bueno L (2003) Probiotics: what are they? What are their effects on gut physiology? Best Pract Res Clin Gastroenterol 177: 11-24.

20. Liong MT (2007) Probiotics: a critical review of their potential role as antihypertensives, immune modulators, hypocholesterolemics, and perimenopausal treatments. Nutr Rev 65: 316-328.

21. Bengmark S (2001) Pre-, pro-and synbiotics. Curr Opin Clin Nutr Metab Care 4: 571-579.

22. Cheruvanky R, Cherukuri R, Pecha R, Drell E (2009) Synbiotics EP 1796473 A4. United States patent application US 11/243,361.

23. Hamasalim $\mathrm{HJ}$ (2016) Synbiotic as feed additives relating to animal health and performance. Adv Microbiol 6: 288-302.

24. Swidsinski A, Ladhoff A, Pernthaler A, Swidsinski S, Loening-Baucke V, et al. (2002) Mucosal flora in inflammatory bowel disease. Gastroenterology 122: 44-54.

25. Ouwehand AC, Isolauri E, Kirjavainen PV, Salminen SJ (1999) Adhesion of four Bifidobacterium strains to human intestinal mucus from subjects in different age groups. FEMS Microbiol Lett 172: 61-64.

26. Piard JC, Desmazeaud M (1991) Inhibiting factors produced by lactic acid bacteria. 1. Oxygen metabolites and catabolism end-products. Le Lait 71: 525-541.

27. Marteau P, Lemann M, Seksik P, Laharie D, Colombe JF, et al. (2006) Ineffectiveness of Lactobacillus johnsonii LA1 for prophylaxis of postoperative recurrence in Crohn's disease: a randomised, double blind, placebo controlled GETAID trial. Gut 55: 842-847.

28. Nemcova R, Bomba A, Gancarcikova S, Herich R, Guba P (1999) Study of the effect of Lactobacillus paracasei and fructooligosaccharides on the faecal microflora in weanling piglets. Berl Munch Tierarztl Wochenschr 112: 225-228.

29. Rastall RA, Gibson GR, Gill HS, Guarner F, Klaenhammer TR, et al. (2005) Modulation of the microbial ecology of the human colon by probiotics, prebiotics and synbiotics to enhance human health: an overview of enabling science and potential applications. FEMS Microbiol Ecol 52: 145-152.

30. Manigandan T, Mangaiyarkarasi SP, Hemalatha R, Hemalatha VT, Murali NP (2010) Probiotics, prebiotics and synbiotics-A review. Biomed Pharmacol J 5: 295-304.

31. Ríos-Covián D, Ruas-Madiedo P, Margolles A, Gueimonde M, de los Reyes-Gavilán CG, et al. (2016) Intestinal short chain fatty acids and their link with diet and human health. Front Microbiol 7: 43
32. Bengmark S (2005) Bio-ecological control of acute pancreatitis: the role of enteral nutrition, pro and synbiotics. Curr Opin Clin Nutr Metab Care 8: 557-561.

33. Oláh A, Belágyi T, Poto L, Romics L, Bengmark S (2007) Synbiotic control of inflammation and infection in severe acute pancreatitis: a prospective, randomized, double blind study. Hepato-gastroenterology 54: 590-594

34. Ghouri YA, Richards DM, Rahimi EF, Krill JT, Jelinek KA, et al. (2014) Systematic review of randomized controlled trials of probiotics, prebiotics, and synbiotics in inflammatory bowel disease. Clin Exp Gastroenterol 7: 473

35. Ohshima T, Kojima Y, Seneviratne CJ, Maeda N (2016) Therapeutic application of synbiotics, a fusion of probiotics and prebiotics, and biogenics as a new concept for oral candida infections: a mini review. Front Microbiol 7: 31.

36. Kotzampassi K, Giamarellos-Bourboulis EJ, Voudouris A, Kazamias P, Eleftheriadis E (2006) Benefits of a synbiotic formula (Synbiotic 2000Forte ${ }^{\oplus}$ ) in critically ill trauma patients: early results of a randomized controlled trial. World J Surg 30: 1848-1855.

37. Spindler-Vesel A, Bengmark S, Vovk I, Cerovic O, Kompan L (2007) Synbiotics, prebiotics, glutamine, or peptide in early enteral nutrition: a randomized study in trauma patients. J Parenter Enteral Nutr 31: 119-126.

38. Kanazawa H, Nagino M, Kamiya S, Komatsu S, Mayumi T, et al. (2005) Synbiotics reduce postoperative infectious complications: a randomized controlled trial in biliary cancer patients undergoing hepatectomy. Langenbeck's Arch Surg 390: 104-113.

39. Sugawara G, Nagino M, Nishio H, Ebata T, Takagi K, et al. (2006) Perioperative synbiotic treatment to prevent postoperative infectious complications in biliary cancer surgery: a randomized controlled trial. Annals Surg 244: 706-714.

40. Rafter J, Bennett M, Caderni G, Clune Y, Hughes R, et al. (2007) Dietary synbiotics reduce cancer risk factors in polypectomized and colon cancer patients. Am J Clin Nutr 85: 488-496.

41. Raman M, Ambalam P, Kondepudi KK, Pithva S, Kothari C, et al. (2013) Potential of probiotics, prebiotics and synbiotics for management of colorectal cancer. Gut Microb 4: 181-192.

42. Gourbeyre P, Denery S, Bodinier M (2011) Probiotics, prebiotics, and synbiotics: impact on the gut immune system and allergic reactions. J Leukoc Biol 89: 685-695.

43. Kivit SD, Saeland E, Kraneveld AD, Kant HJ, Schouten B, et al. (2012) Galectin-9 induced by dietary synbiotics is involved in suppression of allergic symptoms in mice and humans. Allergy 67: 343-352.

44. Knight DJ, Gardiner D, Banks A, Snape SE, Weston VC, et al. (2009) Effect of synbiotic therapy on the incidence of ventilator associated pneumonia in critically ill patients: a randomised, double-blind, placebocontrolled trial. Intensive Care Med 35: 854-861.

45. Scholz-Ahrens KE, Ade P, Marten B, Weber P, Timm W, et al. (2007) Prebiotics, probiotics, and synbiotics affect mineral absorption, bone mineral content, and bone structure. J Nutr 137: 838S-846S.

46. Anderson AD, McNaught CE, Jain PK, MacFie J (2004) Randomised clinical trial of synbiotic therapy in elective surgical patients. Gut 53: 241-245.

47. Rayes N, Seehofer D, Neuhaus P (2009) Prebiotics, probiotics, synbiotics in surgery are they only trendy, truly effective or even dangerous?. Langenbeck's Arch Surg 394: 547-555.

48. Furrie E, Macfarlane S, Kennedy A, Cummings JH, Walsh SV, et al. (2005) Synbiotic therapy (Bifidobacterium longum/Synergy 1) initiates resolution of inflammation in patients with active ulcerative colitis: a randomised controlled pilot trial. Gut 54: 242-249.

49. Jain PK, McNaught CE, Anderson AD, MacFie J, Mitchell CJ (2004) Influence of synbiotic containing Lactobacillus acidophilus La 5, Bifidobacterium lactis Bb 12, Streptococcus thermophilus, Lactobacillus bulgaricus and oligofructose on gut barrier function and sepsis in critically ill patients: a randomised controlled trial. Clin Nutr 23: 467-475. 
Citation: Narnoliya LK, Jadaun JS (2018) Synbiotics: Necessity of Today's Meal. J Bioprocess Biotech 8: 332. doi:10.4172/2155-9821.1000332

Page 5 of 5

50. González-Hernández LA, Jave-Suarez LF, Fafutis-Morris M, MontesSalcedo KE, Valle-Gutierrez LG, et al. (2008) Synbiotic therapy decreases microbial translocation and inflammation and improves immunological status in HIV-infected patients: a double-blind randomized controlled pilot trial. Nutr J 11: 90. 